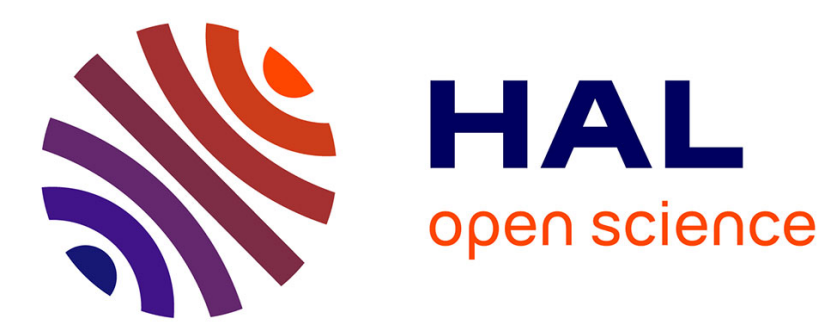

\title{
Network development and excess travel time
}

\author{
Chantal Roucolle, Tatiana Seregina, Miguel Urdanoz
}

\section{To cite this version:}

Chantal Roucolle, Tatiana Seregina, Miguel Urdanoz. Network development and excess travel time.

Transport Policy, 2020, 94, pp.139-152. 10.1016/j.tranpol.2020.04.013 . hal-02865929

\section{HAL Id: hal-02865929 \\ https://hal-enac.archives-ouvertes.fr/hal-02865929}

Submitted on 12 Jun 2020

HAL is a multi-disciplinary open access archive for the deposit and dissemination of scientific research documents, whether they are published or not. The documents may come from teaching and research institutions in France or abroad, or from public or private research centers.
L'archive ouverte pluridisciplinaire $\mathbf{H A L}$, est destinée au dépôt et à la diffusion de documents scientifiques de niveau recherche, publiés ou non, émanant des établissements d'enseignement et de recherche français ou étrangers, des laboratoires publics ou privés. 


\title{
Network Development and Excess Travel Time $\$$
}

\author{
Chantal ROUCOLLE*, Tatiana SEREGINA ${ }^{\dagger}$, Miguel URDANOZ
}

Working paper: March 2020

\begin{abstract}
We study the impact of airline network design on excess travel times for the main US carriers between 2008 and 2017 and find that network configuration affects excess travel time. Based on graph theory and a principal component analysis we build four continuous indicators to measure the airlines networks. We observe that airlines serving more destinations, organizing flights landings and take offs around banks or moving towards a point to point configuration present higher levels of excess travel time. However, there does not seem to exist a preferred network configuration between hub and spoke or point-to-point configuration to reduce excess travel time. We also find a nonlinear impact of competition measured at the citypair level over excess travel time. These results are robust when analyzing observed delays rather than excess travel time.
\end{abstract}

Keywords: Airline, Delay, Congestion, Network.

JEL Classification : C23, C26, L93, L40, L15, L25

\footnotetext{
$\S$ We would like to thank the particpants to the paper presentation at the 2019 ATRS conference in Amsterdam and to the FEE seminar at TBS and the anonymous references for their comments and advice. All remaining errors are ours.

* Ecole Nationale de l'Aviation Civile and Université de Toulouse.

$\dagger$ Ecole Nationale de l'Aviation Civile and TBS Business School

$\ddagger$ TBS Business School
} 


\section{Introduction}

Delays are a widespread phenomenon in air transportation and the problem has been largely studied by researchers. One of the first difficulties faced by researchers is the definition of delays. The US federal aviation administration considers as delayed flights with more than 15 minutes delay. As shown in the literature, the scheduled travel time does not usually match the minimum or average travel time and airlines enlarge or pad their schedule to control for delays (Mayer and Sinai 2003; Deshpande and Arikan 2011; Zhang, Salant, and Van Mieghem 2018). For instance, between 2007 and 2018 more than a half of the US domestic flights arrived before the scheduled time. ${ }^{1}$ The choice of scheduled time usually differs across carriers using the same technology over the same market (Skaltsas 2011; Silke J. Forbes, Lederman, et Yuan 2019).

To avoid the problem of modelling scheduling choices this study analyzes the impact of the network configuration on excess travel time, that is, the difference between the observed arrival time and a theoretical arrival time based on the time technically required under "normal" conditions to fly as defined by Mayer and Sinai (2003). Excess travel time is a measure of airline efficiency in operations: low level of excess travel time corresponds to a higher ability to fly more rapidly among airports. Because passengers are in general more aware of delays than excess travel time, the study presents also the analysis on observed delays. Moreover, most of the literature focuses on studying delays rather than excess travel time. We highlight some differences in the results that should be explained by buffer choices, however the study of buffer or schedule choices is not considered in this article. ${ }^{2}$

Following a long tradition in the literature, this study considers the relationship between airport congestion and excess travel time and the question of internalization of externalities by dominant airlines at airport. The study addresses also the relationship between competition and excess travel time at the city-pair level. We provide some additional insights about the impact of market competition on efficiency. ${ }^{3}$ In addition to these traditional delay's drivers, we add new measures to control for network evolution.

\footnotetext{
${ }^{1}$ Own calculation based on the collected data, presented in section 3.

${ }^{2}$ For recent works on buffer and schedule choices see Fan (2019) or Forbes et al. (2019; 2019).

${ }^{3}$ A market refers to a city pair, for instance New York - Boston, while a route or flight segment refers to an airport-pair, for instance JFK-BOS.
} 
This is the main contribution of this study to the existing literature. We argue that the usual measures used in the empirical literature to describe network organization, in particular hub characteristics, are partial representations of network reality and fail to explain complex network evolutions.

We build four indicators measuring the topological properties of the airline networks and show that they have a significant impact over excess travel time, as well as on delays. Our main result is that airlines increasing their size, measured as the number of city pairs served by the airline, show larger values for excess travel time and delays. According to Basso and Jara Diaz bigger airlines would enjoy economies of spatial scope (2005) however they would suffer longer flights length according to our results. Apart from this size effect, we do not observe that a network configuration is clearly preferred to improve efficiency. A mix of hubbing and point-to-point organization should certainly lead to better performances in terms of excess travel time and delays, a result already suggested by Wojahn (2001) while analyzing airline costs. This mixed organization is observed on the market with airlines supplying both connecting and point-to-point services.

Moreover, our results show a nonlinear relationship between market competition and excess travel time. Some degrees of competition could improve efficiency. In this sense, mergers among airlines could have positive or negative effects in each market depending on the premerger level of competition. Finally, our results suggest that dominant airlines at airport do not internalize the externalities created.

Although the literature has studied the impact of hubbing in the past, up to our knowledge this is the first study to measure the impact of hubbing and other network dimensions with continuous indicators over excess travel time or delays.

We summarize in the next section the literature which has mainly focused on delays rather than on excess travel time. In section 3 we describe our sample, focused on the US domestic market, the network variables and the remaining control variables considered on the analysis. Section 4 presents the estimation and main the results. Section 5 compares the analysis for excess travel time and delays and finally section 6 concludes. 


\section{Literature Review}

There is a large literature on congestion on the air transport sector. The literature tries to study congestion and other factors affecting travel time, distinguishing between scheduled travel time, observed travel time, delays (positive and or negative) and excess travel time. There are few attempts to study the impact of the network configuration in any of these measures. When network configuration is included in the analysis it is usually measured through dummies and is not the main focus.

Following Daniel (1995), there is a large branch of the literature devoted to analyze if congestion, as an externality, is internalized by airlines with large presence at certain airports, where dummies are included to control for large, medium and small hubs. ${ }^{4}$ In this spirit, though results on delay internalization differ across authors, most of them conclude that hubs imply larger delays or travel time: Brueckner (2002; 2004; 2005), Mayer and Sinai (2003) and Bilotkach and Lakew (2019). Ater (2012) studies also concentration although focusing the analysis exclusively on hubs and studying the length of flight banks. Baumgarten et al. (2014) uses the Hubbing Concentration Index (developed by Martín and Voltes-Dorta (2009)) to find a positive effect of hubbing over excess travel time while a negative effect is found over delays, suggesting that airlines increase buffers to reduce the delays suffered by passengers. Fageda and Flores-Fillol (2016) study theoretically and empirically the relationship between congestion and network structure finding that delays are larger for hub networks once concentration and airport size are controlled for, and hub and spoke airlines will tend to internalize less congestion.

Another branch of the literature, started by Suzuki (2000), reviews the relationship between competition and quality levels where delay or on time performance is considered as a quality indicator. In this line, Bubalo and Gaggero (2015) find that, at the European level, the presence of low cost carriers reduces delays at airports and Greenfield (2014) find that competition decreases on time performance. This branch of the literature also considers the hub presence measured by dummies as in Mazzeo (2003) who finds mixed effects of hub presence over delays. Cao et al. (2017) measures hub presence through a continuous variable, the number of destinations served

\footnotetext{
${ }^{4}$ The airport presence is typically measured with the airlines market share at the airport or with the airports Herfindahl Hirschman concentration index.
} 
by each airline from each airport, the higher the number of movements, the more the airport can be considered as a hub, finding also a positive effect over delays.

Rupp (2009) and Bendinelli et al. (2016) combine both approaches, delays as externalities and as quality indicators. However, apart from hubbing, they do not control for network characteristics. Up to our knowledge, the study presented here is the first attempt to measure the impact of network configuration, described by continuous indicators, over excess travel time. Following Bendinelli et al. (2016), our study includes variables to control for concentration both at airport and market levels. Our analysis is based on excess travel time rather than delays since airlines can control for delays announcing longer flights to their passenger, i.e. increasing buffer. ${ }^{5}$ Indeed, buffer is largely used by airlines to reduce delays and has been increasing during the last decades (Forbes, Lederman, and Yuan 2019; Fan 2019).

\section{Data}

\subsection{Data collection}

The two main data sources are the Official Airline Guide (OAG) and the Airline On-Time Performance data (OTP dataset) from the Bureau of Transportation Statistics of U.S. Department of Transportation.

The flight data is collected from OAG, which provides worldwide information on scheduled traffic. The OAG data includes a set of flight characteristics, such as origin and destination airports, distance, departure and arrival scheduled time, as well as the operating carrier, the aircraft type and the number of available seats. The OTP dataset provides information on scheduled time and delays from carriers representing at least 1 percent of the total domestic scheduled-service passenger revenue. In 2017, there were 18 reporting carriers. Consequently, only airlines present in both OTP and OAG will be considered in our analysis.

We focus on one-way passenger domestic flights between 2008 and 2017 operated by US carriers. We study exclusively the month of august to avoid

\footnotetext{
${ }^{5}$ We present the same analysis over delays as a robustness analysis in section 5 .
} 
a seasonality treatment and weather issues (while $38 \%$ of the flights in our sample are delayed, only $1 \%$ of the flights are delayed due to weather issues). ${ }^{6}$

For both databases, OAG and OTP, we recode regional/feeder airlines to their major partners at the carrier-route level. Some extreme observations are deleted from our databases; we delete flights between midnight and 5 am, as they represent less than $1 \%$ of the total flights, and extreme values for the excess travel time and distance (top and bottom corresponding to $1 \%$ of the total sample).

Some macroeconomic variables are collected from different public data sources. Average household income is gathered from the United States Census Bureau, while oil jet fuel spot prices are collected from the US Energy Information Administration. These variables will be used as control or instrumental variables in the forthcoming regressions.

Our final dataset includes 12 carriers (AA, AS, B6, CO, DL, F9, FL, HA, UA, US, VX and $\mathrm{WN})^{7}$ and 3,970,831 flights.

\subsection{Data description}

One observation is a flight characterized by its date and hour of departure and arrival, its operating airline, and its origin and destination airports. Excess travel time is measured at the flight level.

Our interest is to study how airline's Excess Travel Time (ETT) is affected by its network evolution. As stated previously we choose to study excess travel time to get rid of buffer time included in scheduled time by airlines. Excess travel time is a measure of airline quality of services. However, we also run regressions on delays to check if results are robust to such choice.

Excess travel time is computed, for each flight, looking at the difference between the scheduled departure time, the real arrival time and the minimum technically required time to do such trip. The minimum required time per route is calculated thanks to the distribution of real travel time per route observed on the sample. The minimum required time corresponds to the

\footnotetext{
${ }^{6}$ Our database includes also the months of july and september (third quarter). This data is used for robustness analysis in the construction of the network indicators.

${ }^{7}$ American Airlines (AA), Alaska Airlines (AS), JetBlue (B6), Continental Airlines (CO), Delta Airlines (DL), Frontier Airline (F9), AirTran Airways (FL), Hawaiian Airlines (HA), United Airlines (UA), US Airlines (US), Virgin America (VX) and Southwest Airlines (WN).
} 
lowest values of the real time distribution. We have tested several percentiles: 5th, 10th and 25th. The results are robust to this choice: we present them using the $5^{\text {th }}$ percentile.

\subsection{Network indicators as control variables}

Our focus variables are the network evolution indicators. In order to obtain simple continuous indicators measuring the evolution of the airline's networks, we study eleven graph theory measures for each of the airlines during the studied period, plus two measures of network connectivity and size. These measures are built from information compiled at OAG, and they study different topological properties of the networks. We summarize the information from these measures applying a principal component analysis that results into four indicators as explained in Appendix A. As shows Table A5, the main contribution for the last two components comes from single variables, the measures of network size and connectivity. Therefore, we exclude these two variables and perform a PCA analysis on the eleven graph theory measures obtaining two indicators that explain $81.5 \%$ of the original measure variability. ${ }^{8}$

The two indicators and the two measures of network size and connectivity are the four indicators that describe airline network configuration. They are expressed in terms of differences and altogether they represent network evolution.

The first indicator, NetCenterGrowth is correlated with seven graph theory measures calculated at the node or airport level. It can be interpreted as an indicator of the presence of central nodes in the network, or as an indicator of a network topology ranging from point-to-point configuration to a star topology. A positive value of this indicator corresponds to network configuration getting closer to a star configuration. Reversely, a negative value of the indicator should imply that the network is getting closer to a point-to-point structure. Notice that this indicator may differ from the notion of Hub. The presence of hub airports implies that connections are proposed to passengers among the flights arriving and departing from a given airport that are usually organized around banks to reduce connection time.

\footnotetext{
${ }^{8}$ The methodology to obtain these indicators is explained in details in Roucolle et al. (2020). Compared to this article, we add a new measure based on connectivity as explained in Appendix A. We thank our anonymous referee for this suggestion during the revision process of Roucolle et al. (2020).
} 
NetCenterGrowth exclusively analyzes if an airport is central, in the airlines network.

The second indicator, NetWeaveGrowth is strongly correlated with three graph theory measures. It increases with density, transitivity and decreases with mean eigenvector centrality. This component can be viewed as a measure of network interlacing. A positive value of the second indicator may reflect that the network is proposing more alternative routings involving non-stop and one-stop flights, whereas a negative value shows that the network contains fewer and fewer alternative paths to attain a destination.

The third indicator, NetConnectivityGrowth, is based on the scheduled proposed by each airline and analyses how many potential connections can be stablished for each flight arriving at an airport. NetConnectivityGrowth measures the proportion of possible connections with respect to all the flights, direct or connected proposed by an airline. ${ }^{9}$ A positive value indicates that the airline is organizing more and more its flights around banks.

Finally, NetSizeGrowth measures the evolution of the size of the network determined by the number of flight segments, i.e., the number of non-directional city pairs that are offered with nonstop flights. A positive value represents an increase in the number of supplied flights segments. The measure is independent of the flight frequencies.

\subsection{Other control Variables}

In addition to network indicators, we introduce in the analysis of excess travel time (ETT) some traditional factors in the empirical literature and that have been proven to impact delays. Table 1 presents the list and some statistics of the variables included in our analysis.

Customers can perceive ETT as a measure of quality. Therefore, competition might affect ETT. Under competitive pressure, airlines have incentives to provide higher quality of service to keep their market share. To measure the impact of competition on ETT, we include the level of concentration for each market, i.e. a city-pair, through the Herfindahl Hirschman Index, or HHI. HHICitySeats is calculated in terms of seats supplied on a city pair. As shown in the literature (Brueckner, Lee, and Singer 2013) competition

\footnotetext{
${ }^{9}$ A detailed description on the indicator construction can be found on Appendix A.
} 
among airlines may occur at city level rather than at airport level. Thus, we consider city-city markets rather than airport-airport markets for the HHI computation. Following Cao et al. (2017), we introduce HHI in its basic form and in its square form, allowing a non-linear relationship between competition and excess travel time. We expect the excess travel time to decrease with competition.

We introduce a measure of congestion at origin and destination airport (CongestionAtOrigin and CongestionAtDestination). We want to study the number of landings and enplanements around each of the considered flights. To reduce the computational burden, we split the day into 48 half an hour interval and compute the total number of movements at each airport for each 30-minute interval. For each flight, we add the total number of movements during the current, previous and next half an hour, i.e., we measure congestion during a one-hour and half time period around the considered flight departure or arrival. Each flight is therefore associated with two congestion levels at departure and arrival airports. We transform the congestion variables into their logarithm form to smooth the impact of the highest congestion levels. We expect congestion to affect positively excess travel time.

The literature has also largely studied the internalization of congestion by airlines with large market shares at airports. The results in the literature are mixed. To control for the internalization of congestion, we include in the estimation the airline average flight shares at the origin and destination airports, AirlineAirportShare, as in Mazzeo (2003).

We create three different dummies for the recoded airlines: iRECowned indicates if the feeder/regional is owned by a major, iRECone indicates if the feeder/regional is independent but works exclusively for one major and iRECmany indicates if the feeder/regional is independent and works for more than one major. Higher levels of integration should represent lower levels of excess travel time as suggested by Forbes and Lederman (2009). The estimated coefficients will be interpreted as a deviation compared to the referent situation where airline is a legacy carrier.

We include variables controlling for the number of proposed seats in each flight (Seats). The impact of the number of seats is unclear as airlines could put more efforts to reduce delays for larger aircraft and simultaneously suffer longer delays due to the difficulty to manage a larger volume of customers and luggage. 
Table 1. Variables, definitions and summary statistics

\begin{tabular}{|c|c|c|c|}
\hline Variable & Description & Mean & Std. Dev. \\
\hline$E T T$ & Excess travel time at flight level measured in minutes & 23.3461 & 39.5524 \\
\hline NetCenterGrowth & $\begin{array}{l}\text { Yearly evolution of the airline network topology ranging } \\
\text { from point-to-point configuration to a star topology }\end{array}$ & -0.0520 & 1.0125 \\
\hline NetWeaveGrowth & $\begin{array}{l}\text { Yearly evolution of the richness of alternative routings } \\
\text { proposed by an airline }\end{array}$ & 0.0085 & 0.7645 \\
\hline NetConnectivityGrowth & $\begin{array}{l}\text { Yearly evolution of the number of potential connections } \\
\text { proposed by an airline }\end{array}$ & 0.0008 & 0.0389 \\
\hline NetSizeGrowth & $\begin{array}{l}\text { Yearly evolution of the number of connections that are } \\
\text { offered by an airline with nonstop flights }\end{array}$ & 30.5357 & 88.5129 \\
\hline HHICitySeats & $\begin{array}{l}\text { Monthly Herfindahl-Hirschman Index (HHI) between } \\
\text { origin and destination cities according to offered seats }\end{array}$ & 0.6587 & 0.2755 \\
\hline AirlineAirportShare & $\begin{array}{l}\text { Airline's share of total flights, monthly average at origin } \\
\text { and destination airports }\end{array}$ & 0.8654 & 0.3746 \\
\hline iRECowned & $\begin{array}{l}\text { Dummy indicating if a flight is operated by a feeder/re- } \\
\text { gional owned by a major carrier }\end{array}$ & 0.0711 & 0.2569 \\
\hline iRECone & $\begin{array}{l}\text { Dummy indicating if a flight is operated by an inde- } \\
\text { pendent feeder/regional working exclusively for one ma- } \\
\text { jor carrier }\end{array}$ & 0.0228 & 0.1494 \\
\hline iRECmany & $\begin{array}{l}\text { Dummy indicating if a flight is operated by an inde- } \\
\text { pendent feeder/regional working simultaneously for sev- } \\
\text { eral major carriers }\end{array}$ & 0.1995 & 0.3996 \\
\hline Seats & Number of hundred seats available per flight & 1.1953 & 0.4777 \\
\hline OriginAirportSize & Monthly total thousand movements at origin airport & 22.2829 & 19.5727 \\
\hline DestinationAirportSize & $\begin{array}{l}\text { Monthly total thousand movements at destination air- } \\
\text { port }\end{array}$ & 22.1867 & 19.5336 \\
\hline $\begin{array}{l}\text { CongestionAtOrigin } \\
(\log )\end{array}$ & $\begin{array}{l}\text { Number of movements at origin airport in a one hour } \\
\text { and half period around the departure time of the flight }\end{array}$ & 63.7744 & 59.4829 \\
\hline $\begin{array}{l}\text { CongestionAtDestination } \\
(\log )\end{array}$ & $\begin{array}{l}\text { Number of movements at destination airport in a one } \\
\text { hour and half period around the arrival time of the } \\
\text { flight }\end{array}$ & 62.8009 & 59.9360 \\
\hline JetFuelSpotPrice & Monthly jet fuel oil spot price, dollars per gallon & 2.3451 & 0.7074 \\
\hline Instruments & Description & Mean & Std. Dev. \\
\hline RouteMovements & Monthly total hundred movements on an airport pair & 2.7345 & 2.1956 \\
\hline$A v M S O R$ & $\begin{array}{l}\text { Monthly carrier average market share measured at the } \\
\text { airports non present in the considered route }\end{array}$ & 0.3193 & 0.1078 \\
\hline DestTotPopulation & $\begin{array}{l}\text { Total population at destination Metropolitan area (hun- } \\
\text { dred thousands) }\end{array}$ & 43.7925 & 44.9031 \\
\hline DestAvIncome & $\begin{array}{l}\text { Average income (GDP) in thousand US dollars at desti- } \\
\text { nation Metropolitan area }\end{array}$ & 58.072 & 10.2281 \\
\hline
\end{tabular}




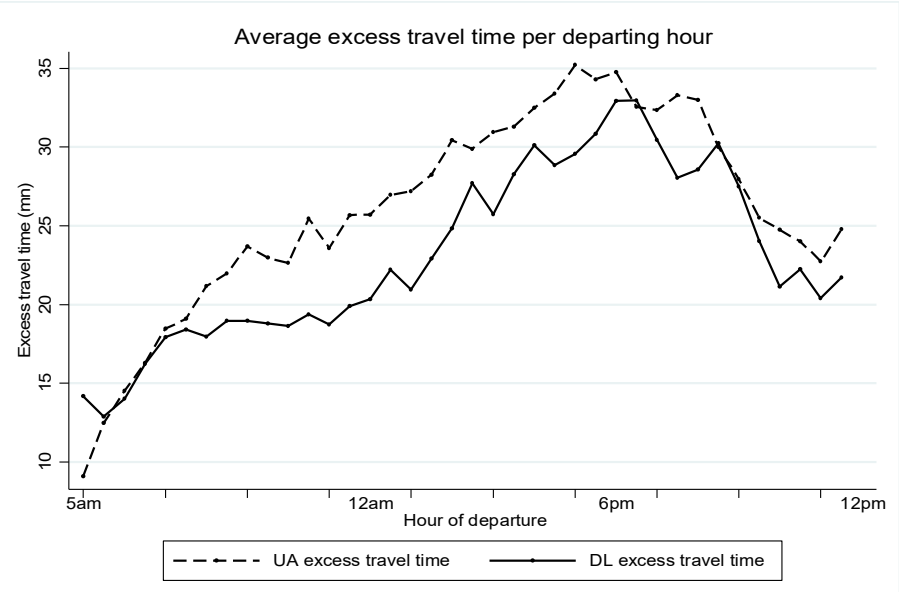

Figure 1. UA and DL average excess travel time per departing hour

Two variables are introduced to control the impact of airport size over excess travel time: the total monthly movements, arrival and departures, at each airport and its square (OriginAirportSize and DestinationAirportSize). Both variables are measured at origin and destination allowing for different effects. We expect those variables to present a positive effect over excess travel time.

We also include monthly jet fuel spot prices, JetFuelSpotPrice. The expected effect is not clear as most of the airlines hedge jet fuel acquisitions.

Finally, we have chosen to include 37 dummies controlling for departures each 30 minutes between $5 \mathrm{am}$ and 12pm. We have excluded flights between midnight and $5 \mathrm{am}$ as they represent less than $0.3 \%$ of the sample. We observe that excess travel time is affected by the departing hour, as shows figure 1. For most of the airlines, ETT increases during the day up to $6 \mathrm{pm}$ and then decreases until mid-night. We expect the values of the dummy coefficients to respect this average tendency.

\section{Estimation}

The use of panel data requires several tests on the database to avoid misleading estimation methods. First, we test for the heteroskedasticity of the errors. The Wald test rejects the null assumption of homoskedasticity. ${ }^{10}$ We use robust errors for the regression. The Brush Pagan test controlling

\footnotetext{
${ }^{10}$ The modified Wald Chi2-Probability for groupwise heteroskedasticity in fixed effect regression model is Prob $>$ Chi $2=0.0000$. We can reject the null assumption of homoskedasticity.
} 
the independence between errors of the model and exogenous variables rejects the null assumption of independence of the errors. ${ }^{11}$ The model is specified as a fixed effect model rather than a random effect model.

The sense of causality between competition (HHICitySeats) and ETT is uncertain, leading to potential endogeneity issues when using an HHI measure as a proxy for competition on a market. Indeed, ETT can affect the airline's market share, and therefore the HHI, as customers can switch to competitor in case of higher ETT. Therefore, ETT affects competition on a given market. For the same reasons, the sense of causality between airport concentration (AirlineAirportShare) and ETT is also uncertain. The variables HHICitySeats and AirlineAirportShare could face endogeneity bias in the absence of endogeneity treatment.

To control these endogeneity concerns, we instrument the market competition and airport concentration by selecting variables that affect their respective levels through size. First, we include RouteMovements, measured as the total number of proposed flights between an airport pair. Second, we consider Hausman-type instruments similarly to Bendinelli et al. (2016), i.e., the average market share of the carriers measured at all the airports but airports of the considered route $\left(A_{V} M S O R\right)$. Third, we introduce socioeconomic variables that can affect competition at both levels, market and airport, such as the total population at destination metropolitan area (DestTotPopulation) and the average household income at the destination metropolitan areas (DestAvIncome). Because we introduce a nonlinear relationship between concentration at market level and excess travel time, we include the level and squared values of RouteMovements. ${ }^{12}$ Several set of instruments have been tested. In particular, the lag of the endogenous variables HHICitySeats has been tested in place of the RouteMovements. ${ }^{13}$ The results are robust to these changes in instruments.

We perform a two stage least square estimation of the following baseline model:

$$
E T T_{i j t}=\beta I_{i t}+\gamma \operatorname{Comp}_{i j t}+\delta Z_{i j t}+d_{i j}+d_{t}+\varepsilon_{i j t}
$$

\footnotetext{
11 The Chibar2-Probability test of the Brush and Pagan Lagragian multilier test for random effects takes the value: Prob $>$ Chibar $2=0.0000$. We can reject the null assumption of independence of the errors and we specify the model as a fixed effect model.

${ }^{12}$ Nonlinearity was also tested for the concentration at the airport level, however results were nonconlusive.

${ }^{13}$ The results are available upon requests.
} 
where the dependent variable is the excess travel time, ETT, for a flight operated by carrier $i$, on route (airport pair) $j$, at date $t$, and is measured on minutes. $I_{i t}$ is a vector including the four indicators allowing to measure the airlines' network evolution, our main interest variables. Comp $p_{i j t}$ includes the competition measures at airport-airline and market (city-pair) level. The remaining control variables are included in vector $Z_{i j t}$ and are airline and/or route and/or time dependent. Finally, we include dummies $d_{i j}$, controlling carrier and airport of origin and destination and $d_{t}$, controlling for time fixed effects. $\epsilon_{i j t}$ represents the error term of the model. Table 2 presents the estimation results for the baseline model and four alternative samples (models 2-4) and variable combinations (model 5).

Several tests are performed to validate the instruments. First, the underidentification test checks the explanatory power of the instruments validating that the model is identified (Kleibergen-Paap LM Chi-sq P$\mathrm{val}=0.0000$ ). Two tests are performed to study if weak identification may be a problem. The Cragg-Donald Wald F test and the Kleibergen-Paap Wald F test. The latter is more appropriate in settings with several endogenous explanatory variables and the presence of heteroskedasticity. Stock and Yogo (2005) provide critical values for this test for up to three endogenous variables. We can confirm the absence of weak instruments, as the obtained statistics are higher than the critical values in the three endogenous variables scenarios.

The Hansen J test for overidentifying restrictions shows that we cannot reject the null hypothesis of our instruments being uncorrelated with the error term (Chi-sq(3) P-val $=0.288)$ : the selected set of instruments is valid for the estimation of the model. Finally, the endogeneity test of endogenous regressors, with Chi2(3) $\mathrm{P}-\mathrm{Val}=0.000$, confirms that we can reject exogeneity of the considered regressors.

Among the network indicators, NetSizeGrowth estimated parameter is positive and statistically significant in all the tested model configurations, suggesting that airlines serving more airport-pairs suffer larger ETT. NetConnectivityGrowth and NetWeaveGrowth are statistically significant and present a positive effect in all model specifications, meaning that on average excess travel time increases when airlines organize flights around banks or modify their network structure towards a point-to-point network. NetCenterGrowth is not significant in most of the analysis considered. 
Table 2. Estimation results

\begin{tabular}{|c|c|c|c|c|c|}
\hline VARIABLES & $\begin{array}{c}(1) \\
\text { Base Model }\end{array}$ & $\begin{array}{c}(2) \\
\text { Large } \\
\text { carriers }\end{array}$ & $\begin{array}{c}(3) \\
\text { Large } \\
\text { airports } \\
\end{array}$ & $\begin{array}{c}(4) \\
\text { Permanent } \\
\text { Markets } \\
\end{array}$ & $\begin{array}{c}(5) \\
\text { No network } \\
\text { indicator }\end{array}$ \\
\hline NetCenterGrowth & $\begin{array}{l}0.00148 \\
(0.0286)\end{array}$ & $\begin{array}{c}-0.126^{* * *} \\
(0.0464)\end{array}$ & $\begin{array}{l}-0.0405 \\
(0.0355)\end{array}$ & $\begin{array}{l}-0.0240 \\
(0.0292)\end{array}$ & \\
\hline NetWeaveGrowth & $\begin{array}{l}0.235^{* * *} \\
(0.0365)\end{array}$ & $\begin{array}{c}0.393^{* * *} \\
(0.0554)\end{array}$ & $\begin{array}{l}0.0966^{* *} \\
(0.0435)\end{array}$ & $\begin{array}{l}0.263^{* * *} \\
(0.0370)\end{array}$ & \\
\hline $\begin{array}{l}\text { NetConnectivity- } \\
\text { Growth }\end{array}$ & $\begin{array}{c}2.123^{* * *} \\
(0.575)\end{array}$ & $\begin{array}{c}12.40^{* * *} \\
(3.100)\end{array}$ & $\begin{array}{c}2.815^{* * *} \\
(0.670)\end{array}$ & $\begin{array}{c}1.978^{* * *} \\
(0.586)\end{array}$ & \\
\hline NetSizeGrowth & $\begin{array}{c}0.00901^{* * *} \\
(0.000390)\end{array}$ & $\begin{array}{c}0.00540^{* * *} \\
(0.000456)\end{array}$ & $\begin{array}{l}0.0116^{* * *} \\
(0.000519)\end{array}$ & $\begin{array}{c}0.00866^{* * *} \\
(0.000407)\end{array}$ & \\
\hline HHI city seats & $\begin{array}{c}-106.7^{* * *} \\
(10.48)\end{array}$ & $\begin{array}{c}-137.1^{* * *} \\
(11.99)\end{array}$ & $\begin{array}{c}-113.3^{* * *} \\
(12.96)\end{array}$ & $\begin{array}{c}-107.3^{* * *} \\
(10.59)\end{array}$ & $\begin{array}{c}-126.9^{* * *} \\
(10.31)\end{array}$ \\
\hline HHI city seats $\widehat{2}$ & $\begin{array}{c}81.22^{* * *} \\
(7.784)\end{array}$ & $\begin{array}{c}103.5^{* * *} \\
(8.825)\end{array}$ & $\begin{array}{c}92.02^{* * *} \\
(10.02)\end{array}$ & $\begin{array}{c}81.70^{* * *} \\
(7.869)\end{array}$ & $\begin{array}{c}95.76^{* * *} \\
(7.662)\end{array}$ \\
\hline $\begin{array}{l}\text { Airline Airport } \\
\text { Share }\end{array}$ & $\begin{array}{c}14.36^{* * *} \\
(1.147)\end{array}$ & $\begin{array}{c}24.23^{* * *} \\
(1.274)\end{array}$ & $\begin{array}{c}7.543^{* * *} \\
(1.834)\end{array}$ & $\begin{array}{c}13.64^{* * *} \\
(1.219)\end{array}$ & $\begin{array}{c}28.76^{* * *} \\
(0.888)\end{array}$ \\
\hline $\begin{array}{l}\text { Fully integrated } \\
\text { feeder }\end{array}$ & $\begin{array}{c}3.359^{* * *} \\
(0.239)\end{array}$ & $\begin{array}{c}2.787^{* * *} \\
(0.249)\end{array}$ & $\begin{array}{c}5.784^{* * *} \\
(0.306)\end{array}$ & $\begin{array}{c}3.026^{* * *} \\
(0.261)\end{array}$ & $\begin{array}{c}2.570^{* * *} \\
(0.238)\end{array}$ \\
\hline Unique Feeder & $\begin{array}{c}7.484^{* * *} \\
(0.225)\end{array}$ & $\begin{array}{c}6.640 * * * \\
(0.265)\end{array}$ & $\begin{array}{c}6.920^{* * *} \\
(0.318)\end{array}$ & $\begin{array}{c}8.355^{* * *} \\
(0.243)\end{array}$ & $\begin{array}{c}7.624^{* * *} \\
(0.225)\end{array}$ \\
\hline Multiple feeder & $\begin{array}{c}7.160 * * * \\
(0.161)\end{array}$ & $\begin{array}{c}7.023^{* * *} \\
(0.174)\end{array}$ & $\begin{array}{c}6.942^{* * *} \\
(0.190)\end{array}$ & $\begin{array}{c}7.093^{* * *} \\
(0.166)\end{array}$ & $\begin{array}{c}7.189^{* * *} \\
(0.161)\end{array}$ \\
\hline Seats & $\begin{array}{c}3.313^{* * *} \\
(0.151)\end{array}$ & $\begin{array}{c}2.694^{* * *} \\
(0.169)\end{array}$ & $\begin{array}{c}3.631^{* * *} \\
(0.166)\end{array}$ & $\begin{array}{c}3.321^{* * *} \\
(0.154)\end{array}$ & $\begin{array}{c}2.976^{* * *} \\
(0.150)\end{array}$ \\
\hline Origin Airport Size & $\begin{array}{c}-0.0970 * * * \\
(0.0220)\end{array}$ & $\begin{array}{c}-0.151^{* * *} \\
(0.0243)\end{array}$ & $\begin{array}{l}0.120 * * * \\
(0.0253)\end{array}$ & $\begin{array}{c}-0.0814^{* * *} \\
(0.0231)\end{array}$ & $\begin{array}{c}-0.145^{* * *} \\
(0.0217)\end{array}$ \\
\hline Origin Airport & $0.000565^{* *}$ & $0.00124^{* * *}$ & $-0.00269 * * *$ & 0.000284 & $0.00165^{* * *}$ \\
\hline $\mathrm{Size}^{\widehat{2}}$ & $(0.000262)$ & $(0.000288)$ & $(0.000323)$ & $(0.000270)$ & $(0.000251)$ \\
\hline $\begin{array}{l}\text { Destination Airport } \\
\text { Size }\end{array}$ & $\begin{array}{c}-0.254^{* * *} \\
(0.0219)\end{array}$ & $\begin{array}{c}-0.329 * * * \\
(0.0237)\end{array}$ & $\begin{array}{c}-0.0925^{* * *} \\
(0.0247)\end{array}$ & $\begin{array}{c}-0.263^{* * *} \\
(0.0230)\end{array}$ & $\begin{array}{c}-0.288^{* * *} \\
(0.0218)\end{array}$ \\
\hline Destination & $0.00197^{* * *}$ & $0.00279^{* * *}$ & $-0.000878^{* * *}$ & $0.00195^{* * *}$ & $0.00291^{* * *}$ \\
\hline Airport Size 2 & $(0.000276)$ & $(0.000298)$ & $(0.000338)$ & $(0.000282)$ & $(0.000268)$ \\
\hline Airport Congestion at & $0.238^{* * *}$ & $0.207^{* *}$ & 0.133 & $0.216^{* *}$ & $0.461^{* * *}$ \\
\hline Origin (log) & $(0.0840)$ & $(0.0951)$ & $(0.106)$ & $(0.0878)$ & $(0.0834)$ \\
\hline Airport Congestion & $1.680 * * *$ & $1.788 * * *$ & $2.408 * * *$ & $1.769^{* * *}$ & $1.798^{* * *}$ \\
\hline at Destination (log) & $(0.0588)$ & $(0.0660)$ & $(0.0690)$ & $(0.0607)$ & $(0.0586)$ \\
\hline Jet Fuel Spot Price & $\begin{array}{c}-0.191^{* * *} \\
(0.0441)\end{array}$ & $\begin{array}{l}0.129 * * \\
(0.0509)\end{array}$ & $\begin{array}{c}-0.500^{* * *} \\
(0.0561)\end{array}$ & $\begin{array}{c}-0.129 * * * \\
(0.0471)\end{array}$ & $\begin{array}{l}0.191^{* * *} \\
(0.0417)\end{array}$ \\
\hline Fixed effects & YES & YES & YES & YES & YES \\
\hline Observations & $3,970,831$ & $3,355,339$ & $2,878,438$ & $3,653,809$ & $3,970,831$ \\
\hline Number of groups & 8,341 & 6,022 & 5,624 & 6,140 & 8,341 \\
\hline Log Likelihood & $-2.010 \mathrm{e}+07$ & $-1.700 \mathrm{e}+07$ & $-1.450 \mathrm{e}+07$ & $-1.850 \mathrm{e}+07$ & $-2.010 \mathrm{e}+07$ \\
\hline $\mathrm{R}^{2}$ & 0.023 & 0.020 & 0.026 & 0.024 & 0.020 \\
\hline
\end{tabular}

Note: Robust standard errors in parentheses. All the regressions include fixed effects for route and carrier, day of the week and departure time with dummies for intervals of 30 minutes. ${ }^{* * *} \mathrm{p}<0.01,{ }^{* *} \mathrm{p}<0.05,{ }^{*} \mathrm{p}<0.1$ 
In order to be able to measure the impact of the network evolution on excess travel time, we present several figures representing the marginal effect of the indicators over ETT and the indicators evolution across time. Figure 2 presents the evolutions for Jetblue (B6) and Southwest (WN) while Figure 3 presents the evolution for Delta (DL) and American Airlines (AA). During the period of analysis most of the main US airlines have experienced mergers that can shock the evolution of the network indicators. ${ }^{14}$ When a merger occurred, the merging period is represented in the figures by a shadow area.

Note that the two pairs of graphs present different scales. In all the cases, the top graph represents the marginal effect of the network indicators over ETT, while the bottom one represents the indicators evolution. All the network indicators are measured on differences and for scale imperatives, NetSizeGrowth has been harmonized and is measured in hundreds of city pairs.

In terms of network evolution, we do not observe a clear pattern among airlines as the network evolution differs across them. None of the network indicator seems to be perfectly correlated with another over the period of analysis. ${ }^{15}$ First, on Figure 2, we represent two LCCs, Southwest Airlines (WN) that is usually studied on the literature and Jet Blue (B6), as it is the largest airline not merging during the studied period. ${ }^{16}$

\footnotetext{
14 During the considered time frame six mergers took place among the US domestic carriers. Delta Airlines (DL) and Northwest Airlines (NW) merged between 2008 and 2010. From 2010, these two airlines are considered as one. United Airlines (UA) and Continental Airlines (CO) merged between 2010 and 2012. From 2012, these two airlines are considered as one. Southwest Airlines (WN) acquired AirTran Airways (FL) between 2010 and 2014. From 2015, these two airlines are considered as one. Frontier Airlines (F9) and Midwest Airlines (YX) merged in 2010. From 2011, these two airlines are considered as one. American Airlines (AA) and US Airways (US) merged between 2013 and 2015. From 2016, these two airlines are considered as one. Finally, Alaska Airlines (AS) and Virgin America (VX) merged between 2016 and 2018. From 2018, these two airlines are considered as one.

${ }^{15}$ By construction the two indicators built from PCA are orthogonal.

${ }^{16}$ The grey area corresponds to the period of the merger between Southwest Airlines and Airtran Airways.
} 

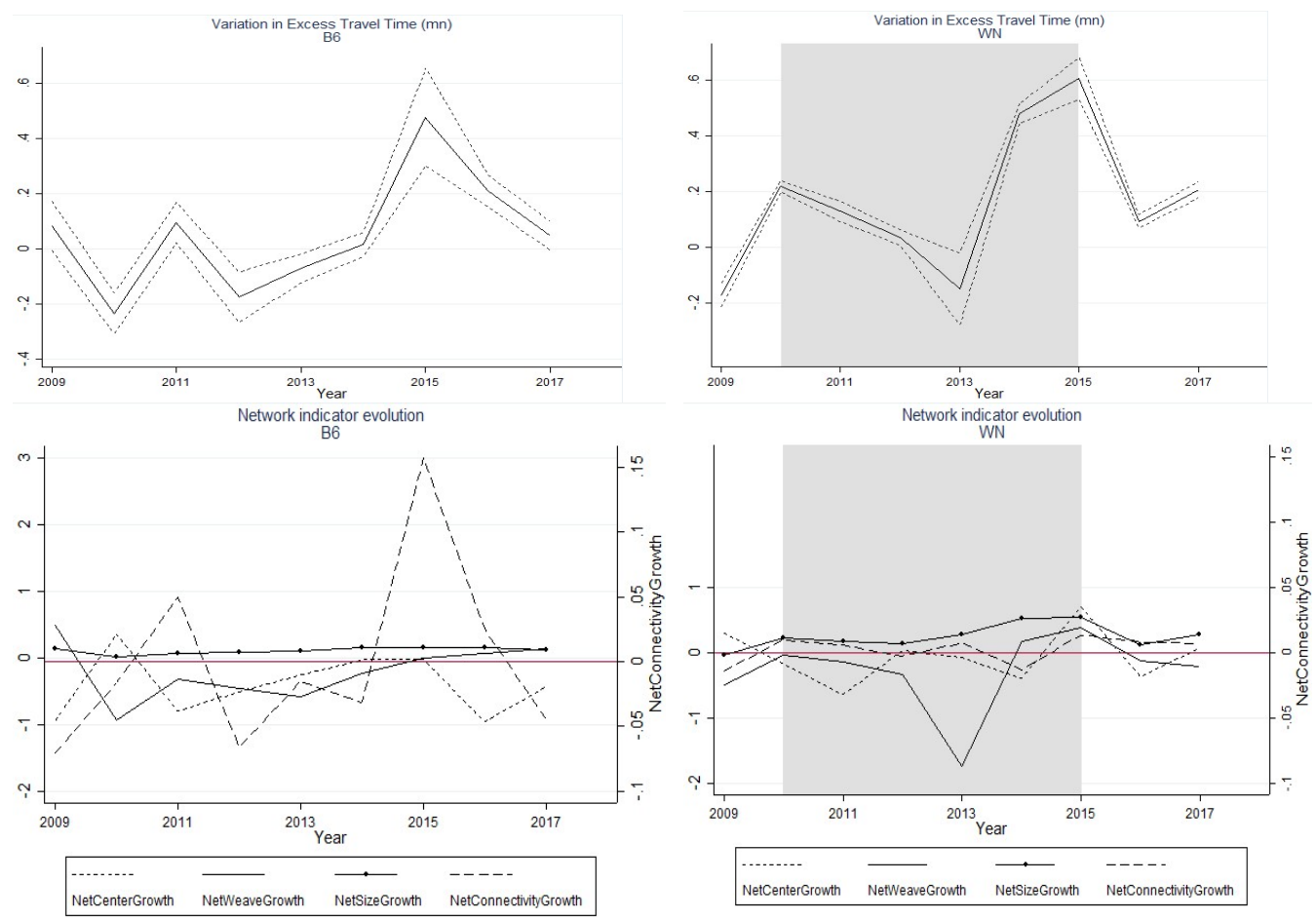

Figure 2. Marginal effects of network indicator on Excess Travel Time - Jetblue (B6) and Southwest Airlines (WN)
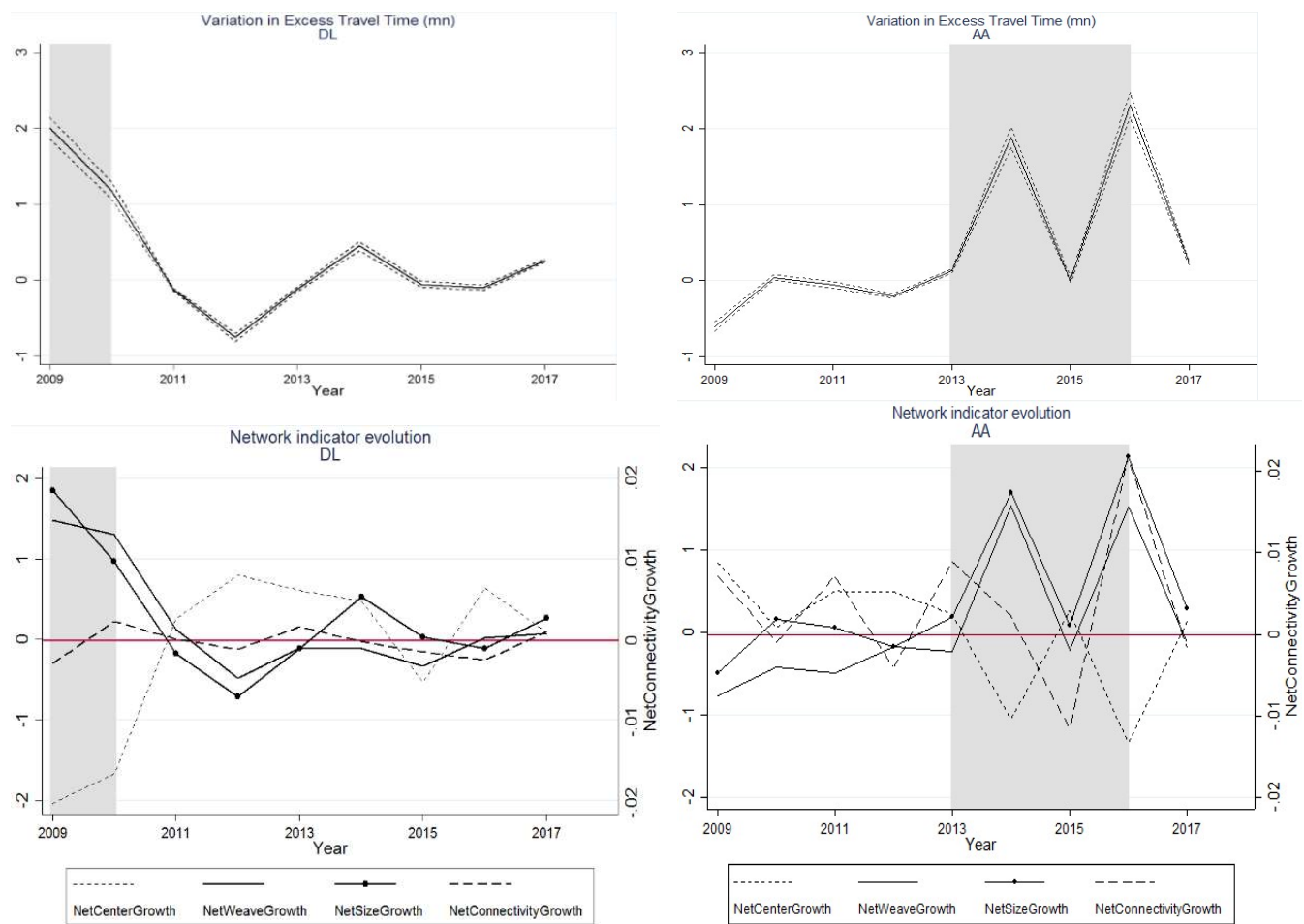

Figure 3. Marginal effects of network indicator on Excess Travel Time - Delta Airlines (DL) and American Airlines (AA) 
The average impact over ETT is small ranging between -0.22 and 0.48 average variation in minutes of ETT. ${ }^{17}$ Other LCCs, such as Frontier Airlines (F9), present higher impacts, equivalent to the ones presented on Figure 3 for Delta Airlines and American Airlines. ${ }^{18}$ These two airlines show a larger impact of the network evolution over ETT, ranging between -0.61 and 2.32 average variation in minutes of ETT. ${ }^{19}$ The marginal impact is larger and positive during the merger period as shown in Figure 3. Up to our knowledge there is no study analyzing the impact of mergers on ETT, however several studies find a positive impact of mergers on delays as in Steven et al. (2016) or Das (2019).

Figure 2 and Figure 3 show that, post-merger, as the network evolution stabilizes, the variation in ETT stabilizes as well. Our continuous indicators allow to observe that the evolution can differ during and after mergers as for instance Delta is able to reduce ETT after the merger period while AA requires a longer period to integrate both airlines.

With respect to the competition measures, first we obtain a nonlinear relationship between competition and ETT at the city pair level, with ETT decreasing when competition increases from a monopoly towards competition at $\mathrm{HHI}=0.66$ and increasing onwards. Therefore, some degree of competition reduces ETT, while extreme cases (monopoly and highly competitive city pairs) suffer longer ETT. Second, the airline airport share shows a positive effect, which suggest a non internalization of delays externalities by airlines. In this sense this work would follow the results suggested by Mazzeo (2003), Rupp (2009) or Bilotkach and Lakew (2019). As can be seen in Table 2 , these results are not affected by the omission of the network indicators in the estimation as shows model (5).

The other control variables present the usual results. Feeders present on average higher ETT, however integrated feeders present lower levels of ETT than non-integrated ones. Higher levels of congestion imply a larger ETT although the effect is larger at the destination airport (as in Cao et al. (2017)). Seats present a positive effect (as in Mazzeo (2003)) suggesting that larger aircrafts may need more time on average to perform the flight given that larger aircrafts will often carry more passengers and luggage. Jet fuel

\footnotetext{
17 The average ETT over the sample is 32.26 minutes for B6, 21.91 minutes for F9 and 21.19 minutes for WN.

${ }^{18}$ Grey areas correspond to the period of the mergers between Delta Airines and Northwest Airlines and between United Airlines and Continental Airlines.

${ }^{19}$ The average ETT over the sample is 24.76 minutes for AA and 23.10 minutes for DL.
} 
prices present a negative sign however the effect is not robust among the different regressions.

Finally, Figure 4 presents the estimated fixed effects according to the departing hour. Everything else constant, excess travel time can differ on average up to 20 minutes according to the departing hour, with the highest levels observed between 6 and $7 \mathrm{pm}$. This is consistent with the descriptive statistics represented in Figure 1. With respect to the day of the week, Mondays, Thursdays and Fridays present the highest ETT while Wednesday and Saturdays present the lowest values.

We implement some series of robustness check in order to test the validity of the estimated model. We use three different subsamples usually analyzed in the literature. The results are largely stable confirming the robustness of the estimated model as shows Table 2.

We first estimate the model focusing on the five main US carriers (model (2)): American Airlines (AA), Southwest Airlines (WN), United Airways (UA), Delta Airlines (DL) and US Airways (US). The sign and significance of the estimated coefficients are unchanged, except for NetCenterGrowth and JetFuelprice. Their values remain on the same magnitude.

We estimate the model on large airports with more than 1,380 thousand flights per month. ${ }^{20}$ The results (model (3)) are robust to the selection of large airports.

Finally, we regress the model on the markets which continue during the full period of observation (model (4)). This test allows avoiding the potential impact of created or vanished markets. The results confirm the robustness of the estimated model. The estimated coefficients are close to the ones of Base model (1).

${ }^{20}$ This subsample represents the $25^{\text {th }}$ percent largest airports. 


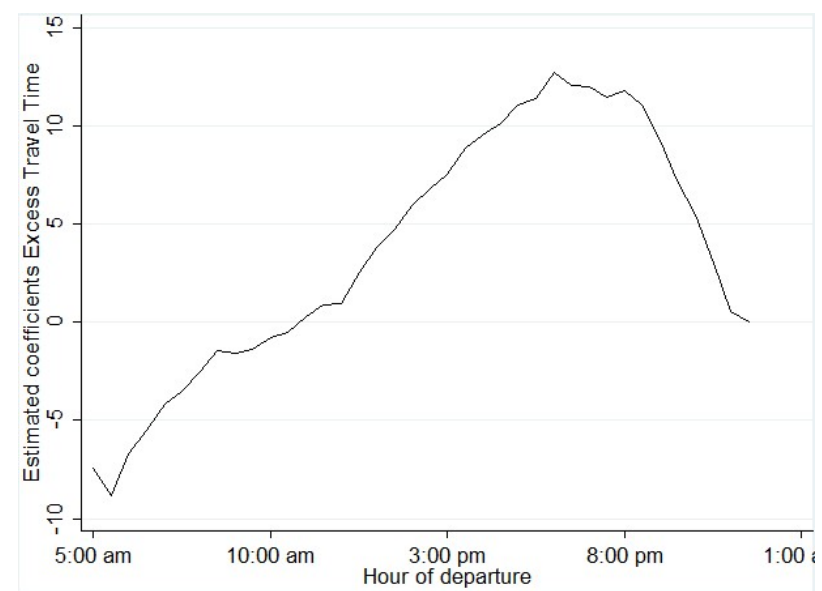

Figure 4. Fixed effect estimation for the departing hour dummies

\section{Excess travel time versus delays}

Although ETT and delays are closely related, the relationship is not necessarily linear as airlines introduce buffer time in their schedules to control for delays. ETT is an indicator of airline efficiency in terms of travelling time. Companies with lower ETT move passengers faster across airports. However, passengers are not usually aware of this and generally only observe delays, measured as the difference between real and scheduled arrival times. In our sample, over a half of the observed flights arrive before schedule and "suffer" negative delays. As Rupp (2009) we estimate our baseline model using several delay measures as endogenous variable to test if the network indicators are still relevant to explain delays. The results that are presented in Table 3 must be interpreted as a robustness analysis for our main results on ETT. Indeed, for a proper estimation of the impact of the network configuration on delays the airline buffer choices should be modelled, this is left for further research.

In column 2 (Table 3) we use the observed arrival delays (including both positive and negative delays) as endogenous variable. Several changes are noticeable with respect to our main results on ETT presented on model 1. First, NetCenterGrowth becomes significant and negative, meaning that flying with carriers with networks moving towards a star configuration enjoy lower arrival delays probably due to larger buffer times. NetSizeGrowth remains positive and significant suggesting that bigger airlines with increasing network sizes suffer longer ETT and longer delays. 
Table 3. Delays estimation results

\begin{tabular}{|c|c|c|c|c|c|}
\hline VARIABLES & $\begin{array}{c}(1) \\
\text { Base Model } \\
\text { ETT }\end{array}$ & $\begin{array}{c}(2) \\
\text { Delay }(+/-)\end{array}$ & $\begin{array}{c}(3) \\
\text { Delay } \geq 15\end{array}$ & $\begin{array}{c}(4) \\
\text { Delay } \geq 30\end{array}$ & $\begin{array}{c}(5) \\
\text { Delay } \geq 60\end{array}$ \\
\hline NetCenterGrowth & $\begin{array}{l}0.00148 \\
(0.0286)\end{array}$ & $\begin{array}{c}-0.205^{* * *} \\
(0.0286)\end{array}$ & $\begin{array}{c}1.630^{* * *} \\
(0.132)\end{array}$ & $\begin{array}{c}2.188^{* * *} \\
(0.198)\end{array}$ & $\begin{array}{c}2.595^{* * *} \\
(0.332)\end{array}$ \\
\hline NetWeaveGrowth & $\begin{array}{l}0.235^{* * * *} \\
(0.0365)\end{array}$ & $\begin{array}{c}0.408 * * * \\
(0.0366)\end{array}$ & $\begin{array}{l}0.308^{* *} \\
(0.135)\end{array}$ & $\begin{array}{l}0.0462 \\
(0.199)\end{array}$ & $\begin{array}{c}-0.785^{* *} \\
(0.332)\end{array}$ \\
\hline NetConnectivity & $2.123^{* * *}$ & $6.995^{* * *}$ & $-16.83^{* * *}$ & $-23.37^{* * *}$ & $-24.93^{* * *}$ \\
\hline Growth & $(0.575)$ & $(0.576)$ & $(2.099)$ & $(2.934)$ & $(4.595)$ \\
\hline NetSizeGrowth & $\begin{array}{c}0.00901^{* * *} \\
(0.000390)\end{array}$ & $\begin{array}{c}0.00926^{* * *} \\
(0.000390)\end{array}$ & $\begin{array}{l}0.000673 \\
(0.00137)\end{array}$ & $\begin{array}{c}0.00299 \\
(0.00190)\end{array}$ & $\begin{array}{c}0.0104^{* * *} \\
(0.00294)\end{array}$ \\
\hline HHI city seats & $\begin{array}{c}-106.7^{* * *} \\
(10.48)\end{array}$ & $\begin{array}{c}-106.6^{* * *} \\
(10.43)\end{array}$ & $\begin{array}{c}-137.9^{* * *} \\
(31.22)\end{array}$ & $\begin{array}{c}-206.0^{* * *} \\
(42.48)\end{array}$ & $\begin{array}{c}-265.3^{* * *} \\
(67.66)\end{array}$ \\
\hline HHIcity seats $\widehat{2}$ & $\begin{array}{c}81.22^{* * *} \\
(7.784)\end{array}$ & $\begin{array}{c}81.55^{* * *} \\
(7.745)\end{array}$ & $\begin{array}{c}100.4^{* * *} \\
(23.44)\end{array}$ & $\begin{array}{c}151.8^{* * *} \\
(31.96)\end{array}$ & $\begin{array}{c}197.4^{* * *} \\
(50.94)\end{array}$ \\
\hline Airport Share & $\begin{array}{c}14.36^{* * *} \\
(1.147)\end{array}$ & $\begin{array}{c}7.761^{* * *} \\
(1.148)\end{array}$ & $\begin{array}{c}66.80^{* * *} \\
(4.003)\end{array}$ & $\begin{array}{c}84.30 * * * \\
(5.457)\end{array}$ & $\begin{array}{c}95.93^{* * *} \\
(8.342)\end{array}$ \\
\hline $\begin{array}{l}\text { Fully integrated } \\
\text { feeder }\end{array}$ & $\begin{array}{c}3.359^{* * *} \\
(0.239)\end{array}$ & $\begin{array}{c}4.740^{* * *} \\
(0.239)\end{array}$ & $\begin{array}{c}-11.32^{* * *} \\
(0.844)\end{array}$ & $\begin{array}{c}-13.20^{* * *} \\
(1.191)\end{array}$ & $\begin{array}{c}-13.59^{* * *} \\
(1.930)\end{array}$ \\
\hline Unique Feeder & $\begin{array}{c}7.484^{* * *} \\
(0.225)\end{array}$ & $\begin{array}{c}8.749 * * * \\
(0.225)\end{array}$ & $\begin{array}{c}-3.399^{* * *} \\
(0.802)\end{array}$ & $\begin{array}{c}-5.050^{* * *} \\
(1.116)\end{array}$ & $\begin{array}{c}-7.466^{* * *} \\
(1.722)\end{array}$ \\
\hline Multiple feeder & $\begin{array}{c}7.160 * * * \\
(0.161)\end{array}$ & $\begin{array}{c}8.380 * * * \\
(0.161)\end{array}$ & $\begin{array}{l}1.321^{* *} \\
(0.604)\end{array}$ & $\begin{array}{c}0.674 \\
(0.849)\end{array}$ & $\begin{array}{l}-0.566 \\
(1.338)\end{array}$ \\
\hline Seats & $\begin{array}{c}3.313^{* * * *} \\
(0.151)\end{array}$ & $\begin{array}{c}4.735 * * * \\
(0.151)\end{array}$ & $\begin{array}{c}0.183 \\
(0.545)\end{array}$ & $\begin{array}{l}1.849 * * \\
(0.789)\end{array}$ & $\begin{array}{c}4.964^{* * *} \\
(1.276)\end{array}$ \\
\hline Origin Airport Size & $\begin{array}{c}-0.0970 * * * \\
(0.0220)\end{array}$ & $\begin{array}{c}-0.0839 * * * \\
(0.0219)\end{array}$ & $\begin{array}{l}0.587^{* * *} \\
(0.0806)\end{array}$ & $\begin{array}{c}0.721^{* * *} \\
(0.114)\end{array}$ & $\begin{array}{c}0.836^{* * *} \\
(0.181)\end{array}$ \\
\hline Origin Airport & $0.000565^{* *}$ & 0.00126 *** & $-0.00450 * * *$ & $-0.00511^{* * *}$ & $-0.00607^{* * *}$ \\
\hline Size 2 & $(0.000262)$ & $(0.000261)$ & $(0.000923)$ & $(0.00130)$ & $(0.00206)$ \\
\hline $\begin{array}{l}\text { Destination Airport } \\
\text { Size }\end{array}$ & $\begin{array}{c}-0.254^{* * *} \\
(0.0219)\end{array}$ & $\begin{array}{c}-0.217^{* * *} \\
(0.0219)\end{array}$ & $\begin{array}{l}0.345^{* * *} \\
(0.0810)\end{array}$ & $\begin{array}{c}0.520^{* * *} \\
(0.115)\end{array}$ & $\begin{array}{c}0.790^{* * *} \\
(0.183)\end{array}$ \\
\hline Destination Airport & $0.00197^{* * *}$ & $0.00173 * * *$ & $-0.00602^{* * *}$ & $-0.00775^{* * *}$ & $-0.0101 * * *$ \\
\hline Size $\widehat{2}$ & $(0.000276)$ & $(0.000276)$ & $(0.00103)$ & $(0.00145)$ & $(0.00226)$ \\
\hline $\begin{array}{l}\text { Airport Congestion at } \\
\text { Origin (log) }\end{array}$ & $\begin{array}{c}0.238^{* * *} \\
(0.0840)\end{array}$ & $\begin{array}{c}-0.725^{* * *} \\
(0.0840)\end{array}$ & $\begin{array}{c}-10.97^{* * *} \\
(0.378)\end{array}$ & $\begin{array}{c}-13.09^{* * *} \\
(0.543)\end{array}$ & $\begin{array}{c}-14.01^{* * *} \\
(0.868)\end{array}$ \\
\hline $\begin{array}{l}\text { Airport Congestion } \\
\text { at Destination }(\log )\end{array}$ & $\begin{array}{l}1.680^{* * * *} \\
(0.0588)\end{array}$ & $\begin{array}{l}0.522^{* * *} \\
(0.0588)\end{array}$ & $\begin{array}{c}-4.154^{* * *} \\
(0.199)\end{array}$ & $\begin{array}{c}-4.804^{* * *} \\
(0.285)\end{array}$ & $\begin{array}{c}-5.329^{* * *} \\
(0.471)\end{array}$ \\
\hline Jet Fuel Spot Price & $\begin{array}{c}-0.191^{* * *} \\
(0.0441)\end{array}$ & $\begin{array}{l}0.505^{* * * *} \\
(0.0441)\end{array}$ & $\begin{array}{c}-0.865^{* * *} \\
(0.160)\end{array}$ & $\begin{array}{l}-0.263 \\
(0.223)\end{array}$ & $\begin{array}{l}-0.680^{*} \\
(0.353)\end{array}$ \\
\hline Route and Carrier FE & YES & YES & YES & YES & YES \\
\hline Observations & $3,970,831$ & $3,970,831$ & 778,673 & 480,287 & 241,032 \\
\hline Number of groups & 8,341 & 8,341 & 7,995 & 7,745 & 7,237 \\
\hline Log Likelihood & $-2.010 \mathrm{e}+07$ & $-2.010 \mathrm{e}+07$ & $-4.296 \mathrm{e}+06$ & $-2.701 \mathrm{e}+06$ & $-1.386 \mathrm{e}+06$ \\
\hline R-squared & 0.023 & 0.020 & 0.002 & -0.001 & 0.001 \\
\hline
\end{tabular}

Note: Robust standard errors in parentheses. All the regressions include fixed effects for route and carrier, year, day of the week and departure time with dummies for intervals of 30 minutes. *** $\mathrm{p}<0.01, * * \mathrm{p}<0.05, * \mathrm{p}<0.1$ 
NetConnectivityGrowth remains statistically significant and positive, however the impact is tripled: an increasing network connectivity leads to higher delays. This suggests that buffer time could be on average shorter, compared to airlines with decreasing connectivity values. Interestingly NetWeaveGrowth and NetCenterGrowth present opposite effects over delays, meaning that networks moving towards a star configuration with a central airport suffer on average less delays. No significant change is observed for the control variables.

The Federal Aviation Administration consider as delayed flights with an arrival delay larger than or equal to 15 minutes. ${ }^{21}$ We perform the regression in three subsamples: delays larger than 15, 30 and 60 minutes respectively to check if the network indicators may impact differently larger delays. The results in Table 3 confirm that the network indicators remain relevant to explain larger delays, although they are not all significant in all specifications and their impact differ from the base model (1) or from model (2). For instance, in the three scenarii the effects of NetCenterGrowth and NetConnectivityGrowth are similar but opposite compared to models (1) and (2). Longer delays should be the focus of further analysis including a thoughtful analysis of buffer choices. There are effects that cannot be capture in our analysis, as shown by the differences in impact of the other control variables.

\section{Conclusion}

Our analysis contributes to the empirical literature on the measure of the impact of airline network organization on efficiency. The relationship between hubs and airline's efficiency (delays, cost, profits...) has been a concern in the literature for decades. However, airline's networks evolve continuously over time and hubbing is one network characteristic among several characteristics that describe a network configuration.

This study represents a first attempt to measure the impact of airlines network evolution over excess travel time. As consumers do not generally observe excess travel time but delays, we also study the impact of the network evolution over observed delays. We describe network evolution thanks to four continuous indicators, which allow describing the full range of existing networks. In addition to the network evolution impact, we analyze the

\footnotetext{
${ }^{21} 20,43 \%$ of our sample present delays larger than 15 minutes.
} 
effect of competition and congestion at airport and market level respectively, to measure the potential effect of airline dominance or internalization of congestion on efficiency.

All our estimations suggest that airlines increasing the number of destinations served perform worse in terms of excess travel time and delays. Also, according to our estimations, when airlines increase the number of alternative routings, excess travel time increases so that a network organization that moves towards a point-to-point structure leads to more excess travel time. Increases in connectivity leads as well to more excess travel time: reinforcing network organization around banks implies more excess travel time. Instead, when airlines move their networks towards a star structure, organized around a central airport, we do not observe a significant effect over ETT, unless flight arrivals and departures are organized on banks.

We have studied the marginal effects of the indicators over ETT and we do not observe a common trend among all airlines as network evolutions differ among them. The only exception is mergers that represent an increase of ETT in most of the cases although some of the airlines are able to reduce over time such increase thanks to the integration of the airlines' networks.

From our results, there is no precise network configuration evolution that seems to perform better in terms of excess travel time. At least neither a perfect star nor a fully connected network, are optimal to reduce excess travel time. This result is consistent with previous results in the literature stating that a mixed network organization could lead to better performances in terms of cost (Wojahn 2001).

When considering market competition, our results indicate that a certain level of competition is efficient to reduce both excess travel time and delays. The incentives to improve efficiency seems to be higher in oligopolistic markets, while more competitive markets or markets where concentration is high, lead to higher airline inefficiencies. This result could settle the different results found in the literature (Goolsbee et Syverson 2005; Prince et Simon 2015; Gil et Kim 2018; Das 2019)

Finally, when airlines have a larger presence at airports, the excess travel time increases. This result shows that when the dominance increases at airport, the airline does not internalize the externalities created by its delays.

Our study still presents several limitations. First, international flights should also be considered on the ETT analysis. The network indicators are built considering international flights, given that they determine the full 
network, while we only observe delays for domestic flights. Additionally, all our information is compiled from supply sources. Several studies include competition measures computed from demand. Finally, we have studied ETT and delays but not buffers that is left for further research. 


\section{Bibliography}

Alderighi, Marco, Alessandro Cento, Peter Nijkamp, et Piet Rietveld. 2007. « Assessment of New Hub-and-Spoke and Point-to-Point Airline Network Configurations ». Transport Reviews 27 (5): 529-49. https://doi.org/10.1080/01441640701322552.

Ater, Itai. 2012. "Internalization of congestion at US hub airports ». Journal of Urban Economics $72 \quad(2-3)$ : 196-209. https://doi.org/10.1016/j.jue.2012.05.004.

Basso, Leonardo J., et Sergio R. Jara-Díaz. 2005. "Calculation of Economies of Spatial Scope from Transport Cost Functions with Aggregate Output with an Application to the Airline Industry ». Text. janvier

2005. https://www.ingentaconnect.com/content/lse/jtep/2005/00000039/0000 0001/art00002.

Baumgarten, Patrick, Robert Malina, et Anne Lange. 2014. « The Impact of Hubbing Concentration on Flight Delays within Airline Networks: An Empirical Analysis of the US Domestic Market ». Transportation Research Part E: Logistics and Transportation Review 66 (juin): 103-14. https://doi.org/10.1016/j.tre.2014.03.007.

Bendinelli, William E., Humberto F. A. J. Bettini, et Alessandro V. M. Oliveira. 2016. « Airline delays, congestion internalization and non-price spillover effects of low cost carrier entry ». Transportation Research Part A: Policy and Practice 85 (mars): 39-52. https://doi.org/10.1016/j.tra.2016.01.001.

Bilotkach, Volodymyr, et Paulos Ashebir Lakew. 2019. « Causes and Effects of Air Traffic Delays: Evidence from Aggregated Data ».

Bootsma, P. D. 1997. « Airline Flight Schedule Development - Analysis and design tools for European hinterland hubs - », octobre. https://research.utwente.nl/en/publications/airline-flight-scheduledevelopment-analysis-and-design-tools-for.

Brueckner, Jan K. 2002. " Airport congestion when carriers have market power ». American Economic Review, 1357-1375.

. 2004. « Network Structure and Airline Scheduling ». The Journal of Industrial Economics 52 (2): 291-312.

. 2005. «Internalization of airport congestion: A network analysis ». International Journal of Industrial Organization 23 (7-8): 599-614. https://doi.org/10.1016/j.ijindorg.2005.03.007.

Brueckner, Jan K., Darin Lee, et Ethan Singer. 2013. « City-Pairs Versus Airport-Pairs: A Market-Definition Methodology for the Airline Industry ». Review of Industrial Organization 44 (1): 1-25. https://doi.org/10.1007/s11151-012-9371-7.

Bubalo, Branko, et Alberto A. Gaggero. 2015. « Low-cost carrier competition and airline service quality in Europe ». Transport Policy, Air Transport Economics, 43 (octobre): 23-31. https://doi.org/10.1016/j.tranpol.2015.05.015. 
Cao, Kang Hua, Betty Krier, Chia-Mei Liu, Brian McNamara, et Jerrod Sharpe. 2017. " The Nonlinear Effects of Market Structure on Service Quality: Evidence from the U.S. Airline Industry ». Review of Industrial Organization 51 (1): 43-73. https://doi.org/10.1007/s11151-016-9544-x.

Daniel, Joseph I. 1995. " Congestion pricing and capacity of large hub airports: A bottleneck model with stochastic queues ». Econometrica: Journal of the Econometric Society, 327-370.

Das, Somnath. 2019. « Effect of Merger on Market Price and Product Quality: American and US Airways ». Review of Industrial Organization 55 (3): 339-74. https://doi.org/10.1007/s11151-019-09717-2.

Deshpande, Vinayak, et Mazhar Arikan. 2011. "The Impact of Airline Flight Schedules on Flight Delays ». Manufacturing \& Service Operations Management 14: 423-40. https://doi.org/10.1287/msom.1120.0379.

Fageda, Xavier, et Ricardo Flores-Fillol. 2016. « How do airlines react to airport congestion? The role of networks ». Regional Science and Urban $\begin{array}{llll}\text { Economics } & 56 & \text { (janvier): }\end{array}$ https://doi.org/10.1016/j.regsciurbeco.2015.11.002.

Fan, Terence Ping Ching. 2019. « Schedule Creep - In Search of an Uncongested Baseline Block Time by Examining Scheduled Flight Block Times Worldwide 1986-2016 ». Transportation Research Part A: Policy and Practice 121 (mars): 192-217. https://doi.org/10.1016/j.tra.2019.01.006.

Forbes, Silke J., Mara Lederman, et Michael J. Wither. 2019. « Quality disclosure when firms set their own quality targets ». International Journal of Industrial Organization 62 (janvier): 228-50. https://doi.org/10.1016/j.ijindorg.2018.04.001.

Forbes, Silke J., Mara Lederman, et Zhe Yuan. 2019. « Do Airlines Pad Their Schedules? \ Review of Industrial Organization 54 (1): 61-82. https://doi.org/10.1007/s11151-018-9632-1.

Forbes, Silke Januszewski, et Mara Lederman. 2009. « Adaptation and Vertical Integration in the Airline Industry ». The American Economic Review 99 (5): 1831-49.

Gil, Ricard, et Myongjin Kim. 2018. « Does Competition Increase Quality? Evidence from the US Airline Industry $\gg$.

Goolsbee, Austan, et Chad Syverson. 2005. « How do incumbents respond to the threat of entry? Evidence from the major airlines ». National Bureau of Economic Research. http://www.nber.org/papers/w11072.

Greenfield, Daniel. 2014. « Competition and Service Quality: New Evidence from the Airline Industry ». Economics of Transportation, Special Issue on Airlines and Airports, 3 (1): 80-89. https://doi.org/10.1016/j.ecotra.2013.12.005.

Martín, Juan Carlos, et Augusto Voltes-Dorta. 2009. " A note on how to measure hubbing practices in airline networks ». Transportation Research Part E: Logistics and Transportation Review 45 (1): 250-54. https://doi.org/10.1016/j.tre.2007.07.012. 
Mayer, Christopher, et Todd Sinai. 2003. « Network Effects, Congestion Externalities, and Air Traffic Delays: Or Why Not All Delays Are Evil ». American Economic Review 93 (4): 1194-1215. https://doi.org/10.1257/000282803769206269.

Mazzeo, Michael J. 2003. "Competition and Service Quality in the U.S. Airline Industry ». Review of Industrial Organization 22 (4): 275-96. https://doi.org/10.1023/A:1025565122721.

O’Day, Jason. 2017. « Distances: Let SAS® Do the Heavy Lifting ». 2017. http://support.sas.com/resources/papers/proceedings17/0155-2017.pdf.

Prince, Jeffrey T., et Daniel H. Simon. 2015. " Do Incumbents Improve Service Quality in Response to Entry? Evidence from Airlines' On-Time Performance ». Management Science $61 \quad$ (2): 372-90. https://doi.org/10.1287/mnsc.2014.1918.

Roucolle, Chantal, Tatiana Seregina, et Miguel Urdanoz. 2020. « Measuring the Development of Airline Networks: Comprehensive Indicators ». Transportation Research Part A: Policy and Practice 133 (mars): 303-24. https://doi.org/10.1016/j.tra.2019.12.010.

Rupp, Nicholas G. 2009. « Do carriers internalize congestion costs? Empirical evidence on the internalization question ». Journal of Urban Economics 65 (1): 24-37. https://doi.org/10.1016/j.jue.2008.07.003.

Skaltsas, Gerasimos. 2011. « Analysis of Airline Schedule Padding on U.S. Domestic Routes ». MIT.

Steven, Adams B., Amirhossein Alamdar Yazdi, et Martin Dresner. 2016. « Mergers and Service Quality in the Airline Industry: A Silver Lining for Air Travelers?» Transportation Research Part E: Logistics and Transportation Review $89 \quad$ (mai): $1-13$. https://doi.org/10.1016/j.tre.2016.02.005.

Suzuki, Yoshinori. 2000. « The Relationship between On-Time Performance and Airline Market Share: A New Approach ». Transportation Research Part E: Logistics and Transportation Review 36 (2): 139-54. https://doi.org/10.1016/S1366-5545(99)00026-5.

Wojahn, Oliver W. 2001. " Airline network structure and the gravity model ». Transportation Research Part E: Logistics and Transportation Review 37 (4): 267-79. https://doi.org/10.1016/S1366-5545(00)00026-0.

Zdeb, Mike. 2010. « Driving Distances and Times Using SAS® and Google Maps ». http://support.sas.com/resources/papers/proceedings10/0502010.pdf.

Zhang, Dennis, Yuval Salant, et Jan Albert Van Mieghem. 2018. « Where Did the Time Go? On the Increase in Airline Schedule Padding Over 21 Years ». SSRN Electronic Journal. https://doi.org/10.2139/ssrn.3238457. 


\section{Appendix A: PCA and connectivity ratio}

Following the work proposed by Roucolle et al. (2020) we study 11 graph theory measures and we add a measure of connectivity to include properties linked to hubs and not reflected by the considered topological measures. Following Alderighi et al. (2007) and Bootsma (1997) the connectivity ratio for an airline network is defined as the number of one-stop city pairs divided by the total number of non-stop and one-stop city-pairs.

To calculate the connectivity ratio, we use the scheduled flight dataset and compile yearly for each operating carrier the number of connecting flights. We consider only one-stop connecting flights. The origin and destinations are considered at the city level while connections must be done at the airport level. For instance, if a passenger wants to fly from Bozeman (BZN) to Washington (DCA, IAD), there exists no direct flight. For each airline we measure how many connecting flights through an airport (not a city) can be proposed to attain any of the airports at the origin and destination cities. The connecting flights must satisfy several conditions:

- minimum of two flights proposed per day (in order to reduce computation time);

- keep city-pairs for which there exists at least one possible non-stop connection on each direction.

- min-max connection time at an airport (different for domestic and international flights);

- factor-1.25 or factor 1.50 to identify possible one-stop connections between two airports(cities);

We describe the last two conditions in detail.

\section{Connection Time Condition}

For the condition on the connection time $T_{C c}$, Table A1 shows the min-Max criterion, minimum (mtc) and maximum (MTC), at the airport used by US carriers for different types of connection. 
Table A1. Minimum and maximum times at an airport used by US carriers for different types of connection

\begin{tabular}{lcc}
\hline Type of connection & mtc & MTC \\
\hline US-US & 45 & 180 \\
US-Int, Int-US, Int-Int & 90 & 300 \\
\hline US -domestic market with two US unincorporated \\
territories, Puerto Rico and US Virgin Island \\
Int - international
\end{tabular}

MTC values are the same as suggested by Bootsma (1997). The mtc value for US-US connection type is taken as in Alderighi et al. (2007) for Europe-Europe connections. As for mtc value for international flight connections, Bootsma (1997) set it to be 120 minutes. We reduce this value to 90 minutes considering it more adequate for the flight operated by US airlines in the study period.

\section{Factor-1.25 or Factor-1.50 in Identifying One-Stop Connections}

With the previous conditions, we could end up counting as possible connections paths that are highly unreasonable. If we take the previous example, a flight between Bozeman (BZN) to Washington (DCA, IAD) with a connection via Anchorage in Alaska would satisfy the previous conditions. The criterion proposed by Bootsma (1997) to identify one-stop reasonable connections paths between two airports(cities) is based on the difference between the time of the connecting flight and the time of a direct flight (if a direct flight is not proposed a theoretical time is computed). More precisely, Bootsma proposes the " 1.25 " criterion as follows,

$$
\max (c f)=\max \left(\frac{\text { Time of one-stop connection }}{\text { Time of direct connetion }}\right)=1.25 \text {. }
$$

The routing (circuity) factor $c f=I D T / D T T$, where

$I D T$ - actual in-flight time indirect connection;

$D T T$ - estimated in-flight time of the direct connection.

Maximum $c f$ excludes the 'back-tracking paths', not attractive for passengers. The " 1.25 criterion" thus imposes a connecting flight to last at most 1.25 times a direct one.

To compute $I D T$, we use the dataset of possible one-stop airport connections compiled with min-Max connection time condition. The sum of the two connecting flight durations plus the difference between arrival and departure times (satisfying mtc and MTC conditions) give the total flight time of a possible one-stop connection, IDT.

The computation of estimated time of non-stop flight connection between two airports(cities), DTT, depends on the city pairs. If the carrier already operates a 
direct flight, the flight time of the direct connection is available on the route. If the considered carrier does not operate a flight but other carriers do, their flight time can be considered as a proxy. Still there exists thousands of city pairs combinations with no direct flights, in such cases DTT estimation requires the following two procedures:

1. estimating the flight distance between any two geolocations (in miles) and

2. determining the parameters to calculate flight duration based on this distance.

We calculate the distance (in miles) between an airport(city)-pair from the information on longitude/latitude. The estimated flight distance between two airports(cities), EDistMl_Apt and EDistMl_City respectively, can be obtained using the Haversine formula. This formula calculates the distance between two geolocations as a shortest distance over the earth's surface ignoring any hills:

$$
\begin{aligned}
& a=\sin ^{2}\left(\frac{\Delta \varphi}{2}\right)+\cos \varphi_{1} \cdot \cos \varphi_{2} \cdot \sin ^{2}\left(\frac{\Delta \lambda}{2}\right), \\
& c=2 \cdot \operatorname{atan} 2(\sqrt{a}, \sqrt{(1-a)}), \\
& d=R \cdot c,
\end{aligned}
$$

where $\varphi$ and $\lambda$ are latitude and longitude respectively, and $R$ is the Earth's radius $(6,371 \mathrm{~km}=3,959 \mathrm{miles})$. The use of this formula needs the $\varphi$ and $\lambda$ to be expressed in radians. ${ }^{22}$

The SAS function GEODIST (see more in O'Day (2017), Zdeb (2010)) is based on the Haversine formula and allows calculating the distance in kilometers, miles, degrees or radians. The input format of the latitude/longitude values can be degrees or radians. In our database the airport(city) coordinates are expressed in decimals, so before applying this function we converted them into radians by multiplying each one by $\pi / 180$. The options 'RM' was specified ( $\mathrm{R}$ - for the input format in radians of the latitude and longitude variables, $\mathrm{M}$ - for the output format in miles of the geodetic distance). We used the SAS function GEODIST to define variables EDistMl_City, EDistMl_Apt.

The "City"-variable [EDistMl_City] will be used when deriving the estimated non-stop flight time, DTT, between two cities. The "Apt"-variable [EDistMl_Apt] is to be taken as a dependent variable in the Time-Distance linear regression analysis. The discovered parameter estimators of the regression model will be further used to calculate the estimated non-stop flight time, i.e. DTT, between any two airports(cities) based on the estimated distance.

\footnotetext{
${ }^{22}$ For instance, to convert latitude and longitude of the JFK airport in New York into radians, these coordinates in degrees.minutes.seconds format $\left(40^{\circ} 38^{\prime} 23^{\prime \prime} \mathrm{N} 073^{\circ} 46^{\prime} 44^{\prime \prime} \mathrm{W}\right)$ must be first converted into decimal format (40.6441666667, -73.7822222222 ), then into radians by multiplying each one by $\pi / 180$, so that latitude $\varphi=0.709374530$ and longitude $\lambda=-1.287742707$.
} 
For the non-stop flights in August 2007 for each origin-destination airport-pair (no matter flight direction) ${ }^{23}$, Table A2 shows descriptive statistics of the differences between estimated distances returned by the SAS function GEODIST and the actual distances as given in OAG data. We denote as resDistMl_Apt the difference between the distances at the airport-pair level and resDistMl_City for citypairs. The table is followed by the figures of their distributions. We can see that GEODIST calculates distance accurately with respect to the OAG database. In $75 \%$ of observations the difference resDistMl_Apt for the airport pairs does not exceed 3 miles $(4.82803 \mathrm{~km})$ and no more than 12 miles $(19.3121 \mathrm{~km})$ in $95 \%$ of observations.

Table A2. Descriptive statistics of resDistMl_Apt and resDistMl_City for US airlines

\begin{tabular}{|c|c|c|c|c|c|c|c|c|}
\hline \multirow{3}{*}{ Variable } & \multirow{3}{*}{$\begin{array}{l}\text { Mean } \\
\text { (St.Dev.) }\end{array}$} & \multicolumn{7}{|c|}{ Quantiles (\%) } \\
\hline & & \multirow[t]{2}{*}{0} & 1 & 5 & 10 & 25 & 50 & 75 \\
\hline & & & & & 90 & 95 & 99 & 100 \\
\hline \multirow[t]{2}{*}{ resDistMl_Apt } & 2.76836511 & \multirow[t]{2}{*}{0} & \multirow[t]{2}{*}{0} & \multirow[t]{2}{*}{0} & 0 & 1 & 1 & 3 \\
\hline & $(3.64905766)$ & & & & 7 & 12 & 17 & 22 \\
\hline \multirow[t]{2}{*}{ resDistMl_City } & 8.9190372 & \multirow[t]{2}{*}{0} & \multirow[t]{2}{*}{0} & \multirow[t]{2}{*}{0} & 1 & 2 & 6 & 12 \\
\hline & $(9.80025702)$ & & & & 20 & 28 & 49 & 76 \\
\hline
\end{tabular}
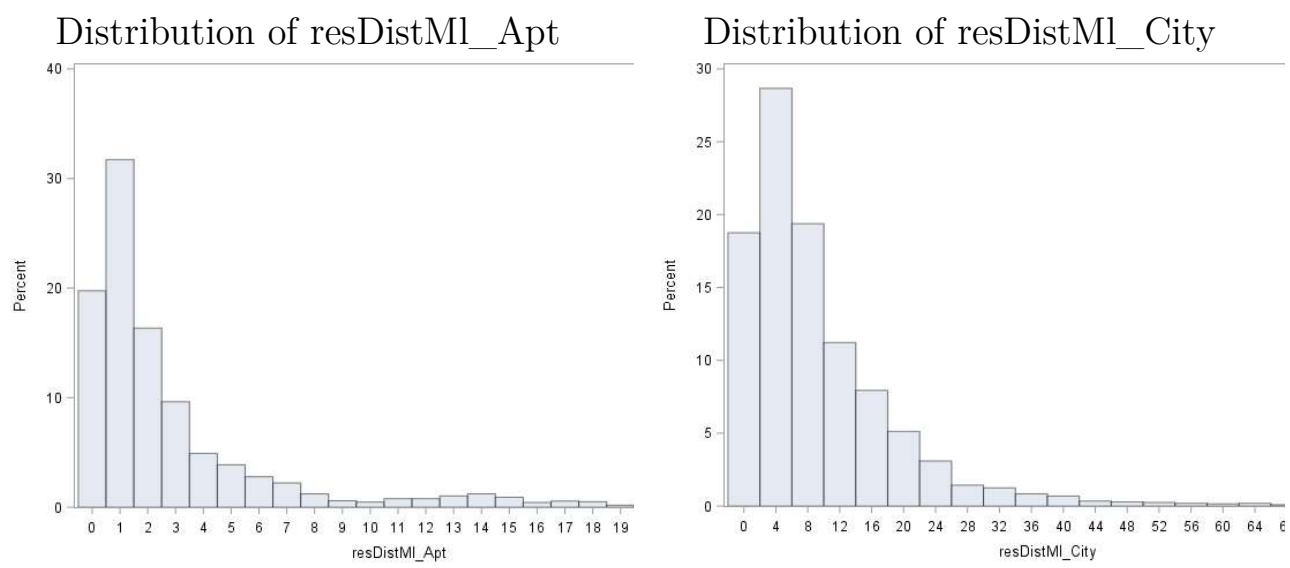

The estimated distance between two airports, calculated as described in the previous step, serves as a basis to obtain estimated non-stop flight time between the two airports. The plot of the data in figure A1 (FDurM on DistMl) shows a generally linear relationship, on average, with a positive slope.

\footnotetext{
${ }^{23}$ Notice that the non-stop flight distance between two airports as given in OAG database remains the same no matter the flight direction or carrier who operates the flight.
} 


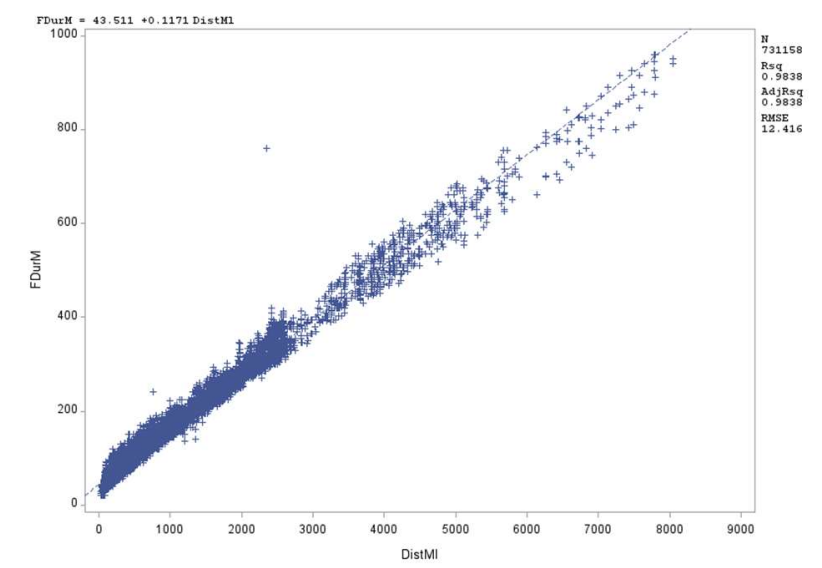

Figure A1. Linear regression analysis of FDurM on DistMl

The linear regression analysis of the model FDurtM $=a+b \cdot$ DistMl for the data in August 2007 returns parameters $\hat{a}=43.511$ and $\hat{b}=0.1171$. The constant term $\hat{a}$ captures the takeoff-landing times ( $\sim 22$ minutes for each takeoff or landing). The coefficient $\hat{b}$ shows that 620 mile (or $\sim 1000 \mathrm{~km}$ ) increase in flight distance adds $0.1171 * 620 \approx 73$ minutes to the total flight duration. This parameter is associated with an average aircraft speed of $512.38 \mathrm{mi} / \mathrm{h}$.

To obtain estimated non-stop flight time, DTT, between any two airports(cities) in our database, we use the formula EFDurtM $=\hat{a}+\hat{b} \cdot$ EDistMl_City, where $\hat{a}, \widehat{b}$ are parameter estimates obtained from the linear regression of FDurM on DistMl yearly on the data in August. Table A3 shows the parameter estimates for each year from 2007-2019 together with root-mean-squared error, i.e. the error for differing the distance of a data point above or below the fitted line.

Table A3. Linear regression of FDurM on DistMl

\begin{tabular}{clll}
\hline Year(August) & \multicolumn{1}{c}{$\hat{b}$} & \multicolumn{1}{c}{$\hat{a}$} & \multicolumn{1}{c}{ RMSE } \\
\hline 2008 & 43.51059368 & 0.1170995058 & 12.416085919 \\
2009 & 43.550579105 & 0.1175595399 & 13.064568068 \\
2010 & 43.189051816 & 0.1171230161 & 12.861380355 \\
2011 & 43.245293807 & 0.1167206194 & 12.505426433 \\
2012 & 42.924182005 & 0.1169540596 & 12.329147971 \\
2013 & 42.965673425 & 0.1167822994 & 18.219435179 \\
2014 & 43.398446349 & 0.1166991177 & 12.000168411 \\
2015 & 45.057112423 & 0.1170881167 & 13.060806043 \\
2016 & 46.13354556 & 0.116186122 & 12.297892449 \\
2017 & 46.818508599 & 0.1163265752 & 12.628752386 \\
2018 & 47.429301331 & 0.1160135332 & 12.983622996 \\
\hline
\end{tabular}


A flight duration consists of takeoff-landing time and time in the air. The regression of flight time on distance shows that flights need on average 45 minutes for takeoff and landing. Therefore, a non-stop flight will take $45^{\prime}+X$ minutes. A connecting flight is composed of two non-stop flights, lasting $Y$ minutes each, plus a connecting time, $T_{C c}$, that can be viewed as $I D T=45^{\prime}+Y+T_{C c}+45^{\prime}+Y .{ }^{24}$ Therefore, given the minimum of the connecting time $T_{C c}$, i.e. mtc, we can express the minimum connecting flight time as, $I D T=m t c+90^{\prime}+2 Y$, or $I D T_{U S}=135^{\prime}+$ $2 Y$ for domestic flights and $I D T_{I N T}=180^{\prime}+2 Y$ for international flights.

Since the sum of in-flight times (the flight time without takeoff/landing) of connecting flight must be no less than that of the direct one, we further take an extreme case assuming that the flight time of these two connecting flights is very close to the flight time of the direct one, i.e. $2 Y=X$. This leads to

$\mathrm{mtc}+90^{\prime}+X \leq 1.25 \cdot\left(45^{\prime}+X\right)$, or $X \geq \frac{90^{\prime}+\mathrm{mtc}-1.25 \cdot 45^{\prime}}{1.25-1}$,

i.e. $X_{U S} \geq 315^{\prime}$ for domestic and $X_{I N T} \geq 495^{\prime}$ for international flights, implying that only non-stop domestic flights lasting at least $315+45$ minutes (6 hours) and international flights lasting $495+45$ minutes (9 hours) can be replaced by connecting flights. This does not adequately match the actual flight situation for U.S. airlines. The criterion proposed by Bootsma (1997) to identify one-stop possible connections between two airports(cities) that was applied to European market must be now adapted to the reality of the flight activity of the U.S. airlines.

Therefore, in addition to the " 1.25 criterion" proposed by Bootsma, we also examine other factors. Table A4 shows minimum time of a non-stop flight (US domestic and international) corresponding to different factors.

Table A4. Minimum non-stop flight time for different factors of identifying one-stop alternatives, US airlines

\begin{tabular}{ccc}
\hline Factor & \multicolumn{2}{c}{$\begin{array}{c}\text { Minimum time (hh:mm) } \\
\text { of a non-stop flight to be compared with } \\
\text { connecting flight alternatives }\end{array}$} \\
\cline { 2 - 3 } & US domestic & INT \\
\hline 1.25 & $6: 00$ & $9: 00$ \\
1.50 & $3: 00$ & $4: 30$ \\
1.75 & $2: 00$ & $3: 00$ \\
2.00 & $1: 30$ & $2: 15$ \\
2.50 & $1: 00$ & $1: 30$ \\
\hline
\end{tabular}

The "1.5 criterion" may be more appropriate for studying the flights operated by U.S. airlines, both domestic and international. This criterion allows minimum 3

\footnotetext{
${ }^{24}$ We assume the same flight duration for the two nonstop flights, $Y$, for simplification. The same conclusions can be obtained with different flight durations assuming that $Y_{1}+Y_{2} \geq X$
} 
hours of a domestic and 4 hours and half for an international non-stop flight duration to be considered as reasonable in comparing with one-stop alternatives.

We keep considering two criteria, "1.25" and "1.50" and calculate the airline connectivity ratios on two datasets that have been obtained following these two criteria, CcRatioCr125 and CcRatioCr150 respectively. The resulting variable of airline connectivity ratio for each of two criteria, 1.25 and 1.50, is tested in PCA together with 11 graph theory measures, following Roucolle et al. (2020): Number of flight segments, Density, Transitivity, Maximum of Degree centrality, Degree centralization, Maximum of Harmonic centrality, Harmonic centralization, Maximum of Betweenness centrality, Betweenness centralization, Mean Eigenvector centrality, Eigenvector centralization. The application of PCA requires stationary variables. Our panel data set does not satisfy the stationarity condition and therefore we perform a PCA based on first differences that could correct for non-stationarity. Table A5 shows the correlations of the four first principal components (PC) with the first differenced variables and the "1.25" criteria. Similar results are obtained with the "1.5" criteria.

Table A5. Correlations with variables

\begin{tabular}{lcccc}
\hline & PC1 & PC2 & PC3 & PC4 \\
\hline$\Delta_{12}$ Connectivity Crit 125 & 0.006 & 0.012 & 0.993 & 0.107 \\
$\Delta_{12}$ Number flight segments & -0.320 & 0.319 & -0.106 & 0.837 \\
$\Delta_{12}$ Density & 0.638 & 0.672 & 0.004 & -0.183 \\
$\Delta_{12}$ Transitivity & 0.008 & 0.782 & 0.034 & -0.250 \\
$\Delta_{12}$ Max. Degree centrality & 0.932 & 0.086 & -0.028 & 0.081 \\
$\Delta_{12}$ Degree centralization & 0.898 & -0.135 & -0.033 & 0.161 \\
$\Delta_{12}$ Max. Harmonic centrality & 0.953 & 0.198 & -0.021 & 0.093 \\
$\Delta_{12}$ Harmonic centralization & 0.888 & -0.230 & -0.029 & 0.096 \\
$\Delta_{12}$ Max. Betweenness centrality & 0.807 & -0.358 & 0.034 & 0.057 \\
$\Delta_{12}$ Betweenness centralization & 0.798 & -0.403 & 0.029 & 0.083 \\
$\Delta_{12}$ Mean Eigenvector centrality & 0.801 & 0.380 & 0.011 & -0.161 \\
$\Delta_{12}$ Eigenvector centralization & -0.035 & -0.881 & -0.009 & -0.209 \\
\hline
\end{tabular}

$\Delta_{12}$ indicates yearly differences

As in Roucolle et al. (2020), we decide to keep the original variables in the case of the last two indicators where the main contribution is coming from a single variable, $\Delta_{12}$ Connectivity Crit 125 and $\Delta_{12}$ Number flight segments. We denote them as NetConnectivityGrowth and NetSizeGrowth respectively. If we exclude 
these two variables from the PCA analysis, the interpretation of the first two components remains the same as shows Table A6.

Table A6. Correlations with variables

\begin{tabular}{lcc}
\hline & PC1 & PC2 \\
\hline$\Delta_{12}$ Density & 0,6490 & $-0,6689$ \\
$\Delta_{12}$ Transitivity & 0,0193 & $-0,7995$ \\
$\Delta_{12}$ Max. Degree centrality & 0,9334 & $-0,0639$ \\
$\Delta_{12}$ Degree centralization & 0,8966 & 0,1618 \\
$\Delta_{12}$ Max. Harmonic centrality & 0,9592 & $-0,1708$ \\
$\Delta_{12}$ Harmonic centralization & 0,8844 & 0,2555 \\
$\Delta_{12}$ Max. Betweenness centrality & 0,8029 & 0,3873 \\
$\Delta_{12}$ Betweenness centralization & 0,7936 & 0,4341 \\
$\Delta_{12}$ Mean Eigenvector centrality & 0,8056 & $-0,3716$ \\
$\Delta_{12}$ Eigenvector centralization & $-0,0629$ & 0,8595 \\
\hline
\end{tabular}

As in Roucolle et al. (2020) component one can be interpreted as NetCenterGrowth and component two as NetWeaveGrowth. 